\title{
Syphilis and Its Cardiovascular Complications in the Elderly
}

\author{
Hiroshi Shibata, M.D., Toshihisa Matsuzaki, M.D., \\ Keiko Shichida, B. of Health Sc., Keisuke Hiraoka, M.D.,* \\ and Masaya Sugtura, M.D.*
}

\begin{abstract}
Summary
The prevalence of syphilis and its cardiovascular complications were investigated in the living population more than 60 years of age. The prevalence of positive serologic test for syphilis (STS) were 16.9\% (124/736) in males and $17.1 \%(236 / 1380)$ in females, which were not statistically different. Aortic regurgitation (AR) was significantly more frequent in those with positive STS $(9.68 \%$ in males, $5.08 \%$ in females) compared with negative STS $(0.98 \%$ in males, $1.75 \%$ in females $)$ in both sexes $(p<0.01)$ and it was marked in males. AR with positive STS had a significantly lower minimal blood pressure than AR with negative STS $(p<0.05)$. Calcifications in the ascending aorta were noticed in 5 out of 24 syphilitic AR. Myocardial infarctions were almost equally found among those with positive STS (1.67\%) and negative STS $(1.65 \%)$, and 2 out of 6 syphilitic cases were complicated by AR. The measurement of the aortic width was not valuable for the diagnosis of uncomplicated syphilitic aortitis.
\end{abstract}

\section{Additional Indexing Words:}

Prevalence of syphilis Serologic test for syphilis Aortic regurgitation Aorto-thoracic ratio Syphilitic aortitis Syphilitic aortic regurgitation

T T has been appropriately stated that cardiovascular syphilis has decreased 1 in recent years due to progress in public health policy and treatment. ${ }^{1)-4)}$ On the other hand it has been pointcd out that cardiovascular syphilis has been concentrated in the elderly, because it usually appears after long latent period.2),5),6) Aortic regurgitation in the elderly is frequently caused by syphilis. ${ }^{\text {?)-11) }}$

The purpose of this paper is to emphasize that in the advanced age, the prevalence rate of syphilis is high and its cardiovascular complications are

From the Tokyo Metropolitan Institute of Gerontology, Department of Epidemiology, 35-2 Sakaecho, Itabashi-ku, Tokyo, 173, Japan.

* Tokyo Metropolitan Geriatric Hospital (Yoiku-in), Department of Internal Medicine, 35-2 Sakaecho, Itabashi-ku, Tokyo, 173, Japan.

Received for publication September 30, 1975. 
still common and important.

\section{Subjects ANd Methods}

This survey was carried out for the period from July 1, 1972 to June 31, 1974. The subjects were the old people who were living in the home for the aged, Yoikuin. There were 736 males and 1,380 females, a total of 2,116, all of whom were over 60 years of age. The diagnosis of syphilis was based on positive serologic test for syphilis of the blood (STS). Other examinations consisted of auscultation, electrocardiograms, and posteroanterior chest X-ray films. Phonocardiograms were recorded on 715 out of 2,116 who were suspected to have valvular diseases and randomly selected.

The following points were observed in the chest X-ray films of all cases; (1) cardio-thoracic ratio (CTR), (2) aorto-thoracic ratio (ATR), measured by the method of Vaquez-Bordet, ${ }^{11)}$ (3) calcification and elongation of the ascending aorta.

\section{Results}

(1) The prevalence rates of syphilis for STS were $16.9 \%(124 / 736)$ in males and $17.1 \%(236 / 1,380)$ in females (Table I). No significant difference was found in the prevalence rates of syphilis between males and females.

(2) Table II shows the distribution of the all types of valvular diseases in this population according to age and sex. There were 29 males and 52 females, a total of 81 cases. They accounted for $3.9 \%$ in male and $3.8 \%$ in females of the population, which were similar for males and females. Aortic regurgitation (AR) was the most frequent, occupying 60\% (50/81) of the all types of valvular diseases. As for AR 24 out of 50 had positive STS. AR had a significantly higher incidence among those with positive STS, com-

Table I. Prevalence of Positive Serologic Test for Syphilis

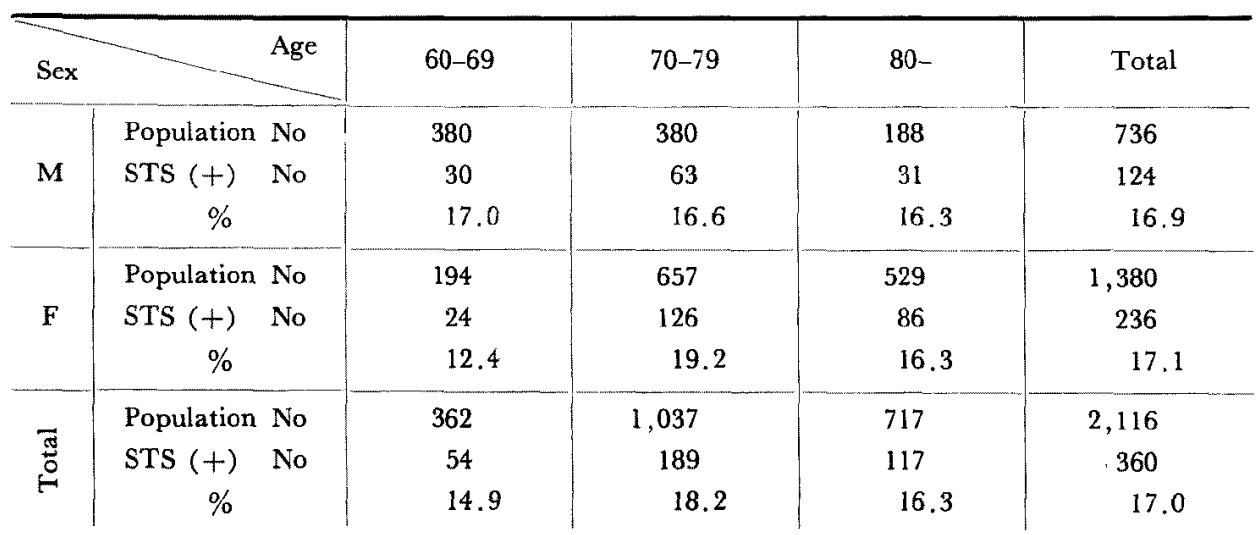


Table II. Age and Sex Distribution of Valvular Disease

\begin{tabular}{|c|c|c|c|c|c|c|c|}
\hline Age & Sex & MR & $\mathrm{AR}$ & $\mathrm{MR}+\mathrm{AR}$ & AS & MSR & \\
\hline \multirow{2}{*}{$60-90$} & M & & $4(3)$ & & & 1 & 5 \\
\hline & $\mathrm{F}$ & & & & & 2 & 2 \\
\hline \multirow{2}{*}{$70-79$} & M & 2 & $12(8)$ & 1 & 1 & & 16 \\
\hline & $\mathrm{F}$ & 2 & $18(7)$ & 1 & 7 & & 28 \\
\hline \multirow{2}{*}{$80-$} & $\mathbf{M}$ & 4 & $3(1)$ & 1 & & & 8 \\
\hline & $\mathrm{F}$ & 5 & $13(4)$ & 3 & 1 & & 22 \\
\hline \multicolumn{2}{|l|}{ Total } & 13 & $50(24)$ & 6 & 9 & 3 & 81 \\
\hline
\end{tabular}

$(\quad)=S T S(+), M R=$ Mital Regurgitation, AR=Aortic Regurgitation, AS = Aortic Stenosis, MSR $=$ Mitral Stenosis \& Regurgitation

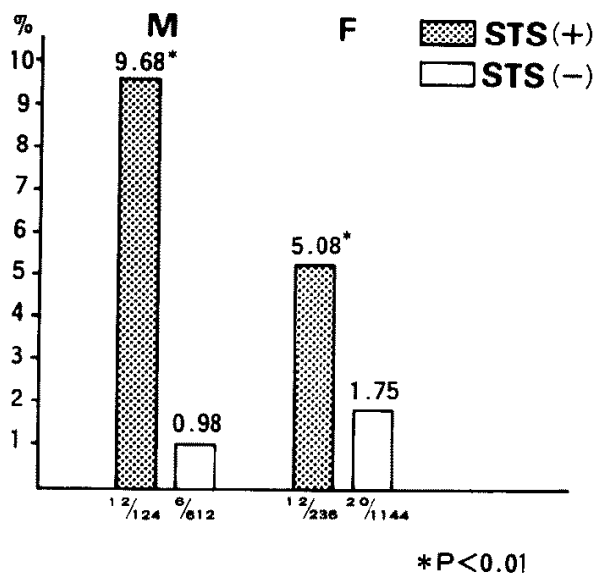

Fig. 1. Comparative incidence of AR among the population with positive and negative STS.

pared with negative STS in both sexes $(\mathrm{p}<0.01)$ (Fig. 1). And it was more marked in males rather than females.

The comparison of the blood pressure between AR with positive and negative STS is indicated in Fig. 2. The AR with positive STS had a higher maximal blood pressure and a lower minimal blood pressure. The difference in the minimal blood pressure was statistically significant $(p<0.05)$. The AR with positive STS had a higher ATR than negative, but statistically not significant (Fig. 3). Calcifications in the ascending aorta were noticed in 5 out of 24 syphilitic AR.

(3) Myocardial infarctions are listed for age, sex, and locations in Table III. The myocardial infarctions were almost equally found among those with positive STS $(1.67 \%)$ and negative STS $(1.65 \%$ ). In 6 cases with positive 


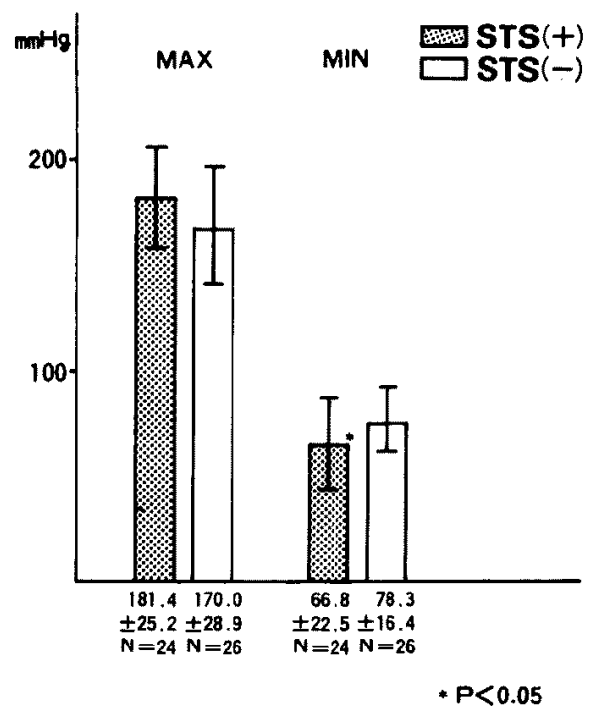

Fig. 2. Comparison of blood pressure between $A R$ with positive and negative STS.

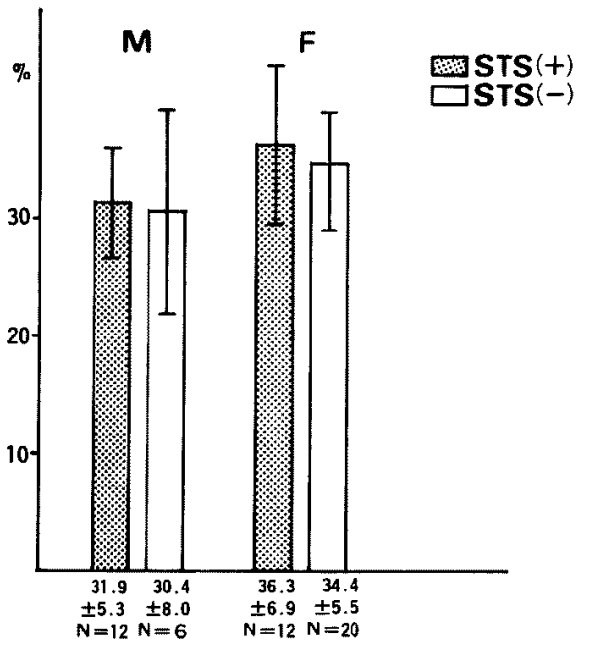

Fig. 3. Comparison of ATR between AR with positive and negative STS.

STS, 2 were complicated by the aortic regurgitation.

(4) The mean values of ATR concerning those without valvular disease or myocardial infarction are shown in Figs. 4 and 5. No tendency was found between 2 groups of positive and negative STS. 
Table III. Comparative Incidence of Myocardial Infarction among the Population with Positive and Negative STS

\begin{tabular}{|c|c|c|c|c|c|c|c|}
\hline & & \multicolumn{5}{|c|}{ Location } & \multirow{3}{*}{ Total } \\
\hline \multirow{2}{*}{\multicolumn{2}{|c|}{ Age }} & \multicolumn{2}{|c|}{$\operatorname{sTS}(+)$} & \multicolumn{3}{|c|}{$\operatorname{STS}(-)$} & \\
\hline & & A & A & A & $\mathrm{P}$ & $A+P$ & \\
\hline \multirow{2}{*}{$60-69$} & $\mathbf{M}$ & 1 & 2 & 4 & & & 7 \\
\hline & $F$ & & & \multicolumn{3}{|c|}{1} & 1 \\
\hline \multirow{2}{*}{$70-79$} & $\mathbf{M}$ & 1 & & \multicolumn{3}{|c|}{5} & 6 \\
\hline & $F$ & 1 & & 3 & 7 & 1 & 12 \\
\hline \multirow[t]{2}{*}{80} & $\mathbf{M}$ & \multirow[t]{2}{*}{7} & & 1 & & & 1 \\
\hline & $F$ & & & 1 & 6 & 1 & 8 \\
\hline Total & & 4 & 2 & 9 & 19 & 1 & \multirow{2}{*}{$35(1.65)$} \\
\hline \multicolumn{2}{|c|}{ Total (\%) } & \multicolumn{2}{|c|}{$6(1.67 \%)$} & \multicolumn{3}{|c|}{$29(1.65 \%)$} & \\
\hline \multicolumn{2}{|c|}{$A=$ Antero-septal } & \multicolumn{5}{|c|}{$\mathbf{P}=$ Postero-inferior } & \\
\hline
\end{tabular}

$\mathbf{M}$

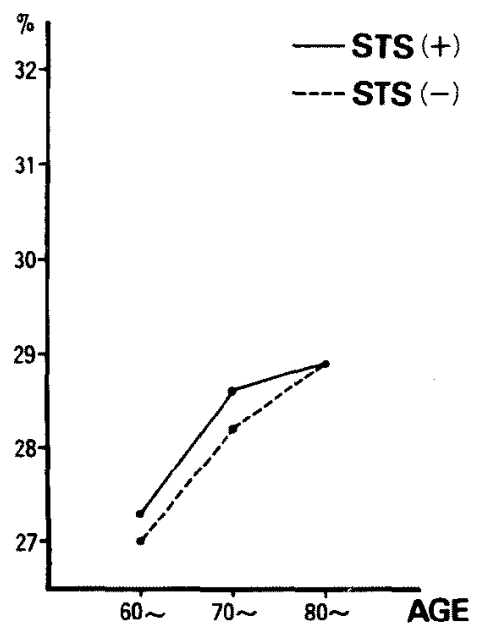

$\mathbf{F}$

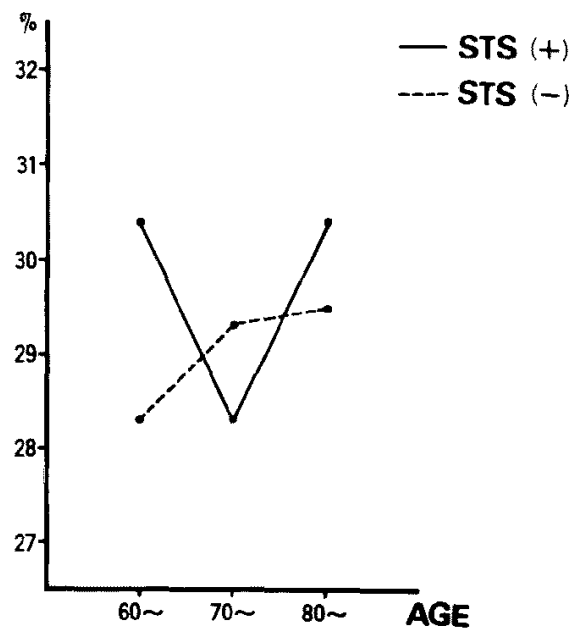

Fig. 4. Mean values of ATR without complication according to sex and age.

\section{Discussion}

The prevalence and morbidity of syphilis had been declining in developed countries, and was lowest at the end of 1955. But since then they have increased steadily. ${ }^{12)}$ A similar tendency has been revealed in our country. ${ }^{13}$ ) The prevalence of syphilis is much different according to age and geographic- 
M

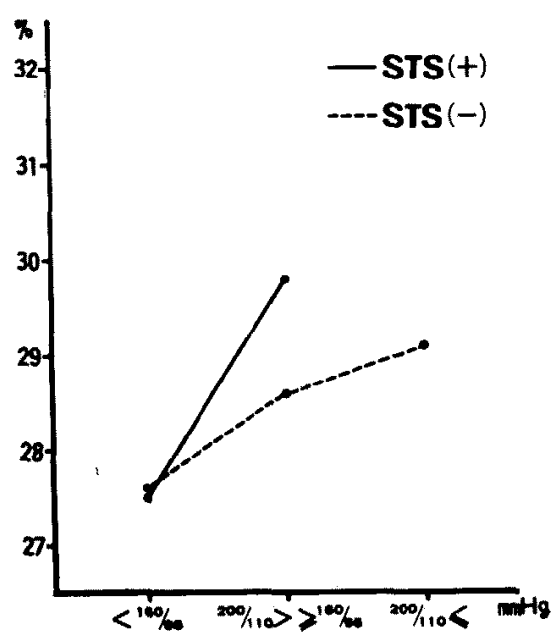

F

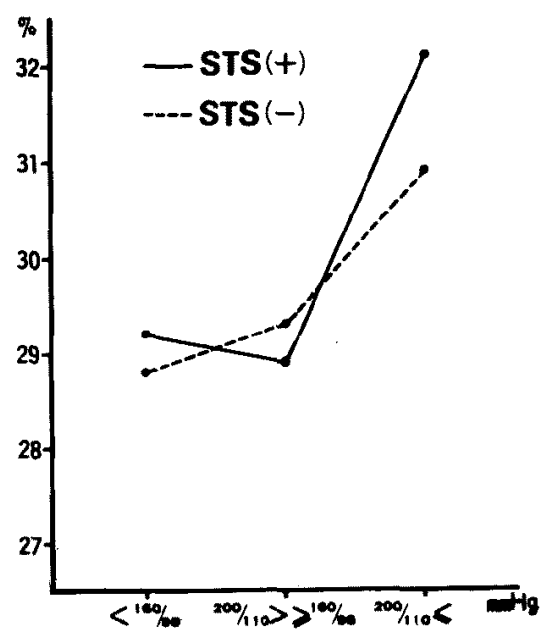

Fig. 5. Mean values of ATR without complication according to sex and blood pressure.

socioeconomic strata. ${ }^{13), 14)}$ The high rate in this study may be due to their advanced age. We investigated the prevalence of STS among centenarians for the period from November 1, 1972 to April 30, 1973, which showed a high rate of $23 \%(17 / 74)$ for positive STS. ${ }^{14}$ )

It is widely accepted that cardiovascular syphilis has decreased in recent years. ${ }^{1)-4)}$ The past 30 years revealed the decline of the rate in autopsy cases from $6.93 \%$ to $0.76 \%{ }^{11-3)}$ But cardiovascular syphilis remains an important clinical problem in the elderly. Aortic regurgitation is the most frequent of all syphilitic heart diseases. It is found in the rate of $0.22 \%{ }^{31}$ or $2.6 \%{ }^{7)}$ in consecutive autopsies. Syphilis is considered to be high in relative frequencies of the various causes of $A R$ in the aged, ${ }^{5)-9), 15)}$ although it has been declining." Syphilitic AR should be carefully differentiated from the AR of other etiology $\mathrm{y}^{8,11), 161,17)}$ and the other types of heart diseases with diastolic murmur. ${ }^{18)}$ Syphilitic AR was found more frequently in males than females, though the prevalence rates of syphilis were similar for males and females, as shown in this and other reports. ${ }^{13), 14)}$ It may be considered that a higher incidence of syphilitic AR in males might be due to a higher vulnerability to AR in males.

Myocardial infarction infrequently results from syphilitic coronary ostial stenosis. $^{2}$ Hiraoka et al found the myocardial infarctions in 6 out of 11 cases with ostial stenosis and 4 out of 15 cases without it in the autopsy cases of syphilitic AR.7) In our series, 2 cases out of the all syphilitic population 
had the association of AR and myocardial infarction.

It has been stated that the early diagnosis of uncomplicated syphilitic aortitis is difficult. ${ }^{19)}$ Dilatation or elongation of the aorta is nonspecific for syphilitic aortitis in the aged. ${ }^{20}$ ) The measurement of the aortic width was proven to be of little value, ${ }^{19), 20)}$ which was confirmed in this study.

\section{REFERENCES}

1. Welty JW: A necropsy survey of cardiovascular syphilis with particular reference to its decreasing incidence. Am J Med Sci 197: 782, 1939

2. Scharfamn WB, Wallach JB, Angrist A: Myocardial infarction due to syphilitic coronary ostial stenosis. Am Heart J 40:603, 1950

3. Heggtveit HA: Syphilitic aortitis. A clinicopathologic autopsy study of 100 cases, 1950 to 1960. Circulation 29: 346, 1964

4. Barondess JA, Sande M: Some changing aspects of aortic regurgitation. Arch Intern Med 124: 600,1969

5. Sugiura M, Hiraoka K, Shibata H: Syphilitic heart diseasc in the aged. Geriat Med 12: 1435,1974 (in Japanese)

6. Prewitt TA: Syphilitic aortic insufficiency. Its increased incidence in the elderly. JAMA 211: 637,1970

7. Hiraoka K, Ohkawa S, Sugiura M: A clinicopathological study on the syphilitic aortic re-

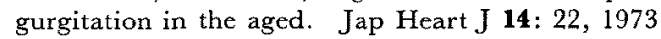

8. Shibata H, Hashimoto H, Matsuzaki T, Sakuma T, Hiraiwa S, Morishima A, Ito Y, Kobayashi $\mathrm{T}$ : Valvular disease after middle age. Epidemiology and clinical study. Shinzo (Heart) 5: 1551, 1973 (in Japanese)

9. Zeman FD, Storch S: Syphilitic heart disease in the aged. Ann Intern Med 36: 1423, 1952

10. Caldwell JG, Price EV, Schroeter AL, Fletcher GF: Aortic regurgitation in the tuskegee. Study of untreated syphilis. J Chron Dis 26: 187, 1973

11. Ueda H, Sakamoto T, Uozumi Z, Kawai N, Yamada T, Inoue K: Aortic valvular disease in the aged. Clinical observations on 206 valvular diseases after sixty years of age. Saishinigaku 22: 2738, 1967 (in Japanese)

12. Fleming WL, Hill G: Ghanging factors in syphilis and other venereal diseases. Arch Environ Health 12: 101, 1966

13. Nito H, Ushio K: Dissemination of syphilis in Yamaguchi prefecture. Report 1. The serologic test for syphilis in dwellers. Research report of prefectural Reseach Institute of Health 3: 51, 1968 (in Japanese)

14. Matsuzaki T, Shichida K, Oba K, Haga H, Ueno H, Sakino S, Shibata H: Epidemiology of centenarian in Japan. Report 1, 2. Jap J Geriat 11: 260, 1974 (in Japanese)

15. Bleich $\mathrm{A}$, Lewis $\mathrm{J}$, Marcus FI: Aortic regurgitation in the elderly. Am Heart J 71: 627, 1969

16. Sugiura M, Okada R, Hiraoka K, Ohkawa S, Shimada $H$ : A new etiological concept of the aortic regurgitation in the aged. Prolapsed cusp due to degeneration. Jap Heart J 10: 20,1969

17. Carter JB, Sethi S, Lee GB, Edwards JE: Prolapse of semilunar cusps as causes of aortic insufficiency. Circulation 43: 922, 1971

18. Shibata $H$, Matsuzaki $T$, Hashimoto $H$, Sakuma $T$, Morishima $A$, Ito $Y$ : Congenital heart disease in forty years of age and over. Prevalence, relative incidence, and clinical features. Jap Girculat J 39: 75, 1975

19. Bosharas S, Hollander L, Goldsmith M: The early diagnosis of syphilitic aortitis. Am J Med Sci 203: 54, 1942

20. Maynard EJ: The present status of the diagnosis of uncomplicated syphilitic aortitis. Bull NY Acad Med 18: 383, 1942 